\title{
ANALISIS FAKTOR PENGGUNAAN FORMALIN PADA PEDAGANG TAHU DI PASAR TRADISIONAL KOTA SERANG
}

\author{
Fauzul Hayat ${ }^{1}$, Darusmini $^{2}$ \\ 1,2 Fakultas Ilmu Kesehatan, Universitas Faletehan Serang, Banten \\ Email: fauzulhayat@yahoo.co.id
}

\begin{abstract}
ABSTRAK
Formalin dikenal sebagai bahan desinfektan, germisida dan pengawet non makanan. Untuk alasan ini, penggunaanya sangat dilarang dalam produk makanan tahu. Pentingnya pencegahan penggunaan formalin pada pedagang tahu berdampak pada kesehatan manusia sehingga aman dikonsumsi. Tujuan penelitian untuk mengetahui faktor penyebab penggunaan formalin pada pedagang tahu di pasar tradisonal Kota Serang. Penelitian ini menggunakan cross sectional dengan tekhnik total sampling. Sampel sebanyak 43 pedagang tahu dan pengambilan sampel tahu sebanyak 43 sampel tahu. Instrumen penelitian menggunakan kuesioner untuk mendapatkan data variabel pengetahuan, sikap dan pengawasan yang sebelumnya telah dilakukan uji validitas ( $\mathrm{r}$ hitung $>\mathrm{r}$ tabel) dan reliabilitas dengan nilai cronbach's alpha $(\alpha)$ yaitu $0,947>0,60$. Pemeriksaan kandungan formalin tahu dilakukan oleh Laboratorium Kesehatan Daerah (Labkesda) Kota Serang menggunakan uji reagensia schiff. Analisis data secara univariat dan bivariat dengan menggunakan uji chi square. Hasil penelitian menunjukkan dari 43 sampel tahu di pasar tradisional Kota Serang, sebanyak 29 sampel tahu (67,4\%) positif mengandung formalin. Tidak ada hubungan antara sikap dengan penggunaan formalin pada pedagang tahu $(p=1,000)$. Ada hubungan antara pengetahuan $(p=0,016)$ dan pengawasan $(p=0,004)$ dengan penggunaan formalin pada pedagang tahu. Penegakan aturan, pembinaan pedagang dan produsen tahu mencegah penggunaan formalin.
\end{abstract}

Kata kunci: Formalin, Pasar Tradisional, Pedagang Tahu 


\title{
FACTOR ANALYSIS OF FORMALIN USE TOFU TRADERS IN TRADITIONAL MARKETS OF SERANG CITY
}

\begin{abstract}
Formalin is known as a disinfectant, germicide and non-food preservative. For this reason, useing formalin in tofu food products is strictly prohibited. The importance of preventing the use of formalin in tofu traders has an impact on human health so it is safe for consumption. The purpose of this study was to determine of formaldehyde used among tofu traders in the traditional market of Serang City. Cross-sectional study with total sampling technique. The research sample was 43 tofu traders and 43 tofu samples were taken. Questionnaire instrument to obtain data on the variables of knowledge, attitudes and supervision variables that had previously been tested for validity ( $r$ count $>r$ table) and reliability with Cronbach's alpha $(\alpha)$ value of $0.947>0.60$. Tofu formalin content examination was carried out by the Regional Health Laboratory (Labkesda) Serang City using the Schiff reagent test. The results showed that there were (67.4\%) tofu trader were positive formalin. There is no relationship between attitudes and use of formaldehyde in tofu traders $(p=1,000)$. There is a relationship between knowledge $(p=0.016)$ and supervision $(p=0.004)$ with the use of formalin in tofu traders. Application of regulations, supervision traders and producers to prevent the use of formaldehyde in food.
\end{abstract}

Keywords: Formalin, Traditional Markets, Tofu Traders

\section{PENDAHULUAN}

Tahu sebagai prodak bahan pangan hasil olahan kedelai merupakan produk makanan yang rentan mengalami kerusakan dan pembusukan. Produsen dan pedagang tahu dengan pertimbangan ekonomis, praktis dan motive lainnya, menambahkan bahan pengawet seperti formalin agar lebih tahan lama. (Desrosier,Norman, 2008)
Larutan konsentrasi formalin sebesar $\quad 10-40 \% \quad$ formaldehida. Penggunaan formalin sebagai bahan non pengawet makanan. Dilarang penggunaanya sebagai pengolahan makanan. (Saparinto,Hidayati,2006) Laporan tahunan Badan Pengawasan Obat dan Makanan (POM) tahun 2018 tentang penggunaan bahan berbahaya pada produk pangan jajanan menemukan dari 282 sampel jenis pangan termasuk didalamnya 
produk tahu didapatkan sebesar 37,8\% mengandung formalin. (BPOM,2018) Monitoring lapangan yang dilakukan oleh Dinas Kesehatan Kota Serang tahun 2017 menemukan adanya tahu berformalin yang dijual sejumlah pedagang di Pasar lama dan Pasar Induk Rau (PIR) Serang. Pemeriksaan sampel tahu sebanyak 12, terdapat empat tahu putih $(33,3 \%)$ positif berformalin. (Dinkes Kota Serang, 2017) Penelitian yang dilakukan oleh Lakuto dkk, (2017) menemukan bahwa tahu berformalain sebanyak 13 positif $(92,8 \%)$ di Pasar Bersehati Kota Manado. Penelitian Syarfaini, Rusmin (2014), menemukan bahwa dari 15 sampel tahu di delapan pasar tradisonal Kota Makassar sebanyak 5 sampel tahu $(33,3 \%)$ positif mengandung formalin.

Upaya untuk meningkatkan pengetahuan dan kesadaran pedagang tahu mengidentifikasi formalin, bahaya penggunaan dan pengolahan makanan dapat meningkatkan keamanan bahan pangan dan kesehatan masyarakat. (Wijaya dkk, 2011) Penelitian Arumsari dkk, (2017), menemukan pengetahuan sebagai faktor perilaku penggunaan formalin pada pedagang dan produsen mie basah dan tahu di Provinsi DKI Jakarta.
Hal tersebut berdasarkan wawancara mendalam diketahui formalin merupakan bahan pengawet, dan dilarang pemakaiannya. Pedagang pasar tidak mengetahui bentuk, sifat dan kegunannya, tetapi mengerti formalin berbahaya bagi manusia, dengan keyakinan tidak berefek pada kesehatan. Adanya pemahaman bahwa formalin dalam jumlah kecil tidak berdampak kesehatan. Sikap merupakan faktor pendorong seseorang untuk berperilaku baik. Sikap tidak baik bertentangan dengan norma yang berlaku di masyarakat. Penelitian yang dilakukan oleh Arumsari dkk, (2017), menemukan bahwa sikap berpengaruh terhadap perilaku masyarakat.

Peran pemerintah untuk penegakan hukum, pembinaan pedagang dan produsen tahun mencegah pemakaian bahan pengawet pangan. (Sutiari, Dwipayanti, 2011) Pencegahan dan pengendalian dilakukan instansi kesehatan, Badan POM daerah, Dinas Perindustrian dan keterlibatan komunitas daerah. (Hartati,2007)

Berdasarkan hal diatas, maka tujuan penelitian dilakukan untuk mengetahui faktor penyebab penggunaan 
formalin pada pedagang tahu di Pasar Tradisonal Kota Serang.

\section{METODE PENELITIAN}

Penelitian dengan studi cross sectional. (Arikunto,2010) Penelitian dilaksanakan September-Desember 2019. Populasi didapatkan dari seluruh pedagang tahu di pasar tradisional wilayah Kota Serang. Sampel merupakan total populasi sebanyak 43 pedagang tahu dan pengambilan sampel tahu diantaranya pasar lama sebanyak 5 sampel tahu, pasar taman sari sebanyak 8 sampel tahu, pasar rau sebanyak 27 sampel tahu, dan pasar kalodran sebanyak 3 sampel tahu. Variabel bebas diantaranya pengetahuan, sikap dan pengawasan. Variabel terikat penelitian yaitu kandungan formalin tahu. Data primer didapatkan dengan melakukan wawancara dengan pedagang tahu menggunakan kuesioner terstruktur untuk mendapatkan data variabel pengetahuan, sikap dan pengawasan. Instrumen penelitian menggunakan kuesioner untuk mendapatkan data variabel pengetahuan, sikap dan pengawasan dengan uji validitas dan reliabilitas yaitu $0.947>0,60$. Pemeriksaan kandungan formalin tahu dilakukan oleh Laboratorium Kesehatan Daerah (Labkesda) Kota Serang menggunakan uji reagensia schiff. Data analisis berupa univariat dan bivariat.

\section{HASIL DAN PEMBAHASAN}

Karakteristik responden dari 43 pedagang tahu di pasar tradisional Kota Serang, sebanyak 32 pedagang tahu berusia 26-45 tahun (74,4\%). Sebagian responden berjenis kelamin laki-laki $(58,1 \%)$ pendidikan SMP sebesar $(44,2 \%)$. Dapat dilihat pada tabel 1.

Tabel 1. Distribusi frekuensi berdasarkan karakteristik pedagang tahu di pasar tradisional Kota Serang

\begin{tabular}{clcc}
\hline No. & \multicolumn{1}{c}{ Karakteristik } & Frekuensi & $\mathbf{( \% )}$ \\
\hline 1. & Usia & 7 & \\
& 18-25 tahun & 32 & 16,3 \\
& 26-45 tahun & 4 & 74,4 \\
& 46-60 tahun & & 9,3 \\
2. & Jenis Kelamin & 25 & 58,1 \\
& Laki-Laki & 18 & 41,9 \\
3. & Perempuan & &
\end{tabular}




Tidak Tamat SD
Tamat SD
SMP
SMA

Tabel 2. Distribusi frekuensi kandungan formalin pedagang tahu di pasar tradisional Kota Serang

\begin{tabular}{cccc}
\hline No. & Kandungan Formalin Tahu & Frekuensi & $(\%)$ \\
\hline 1. & Positif & 29 & 67,4 \\
2. & Negatif & 14 & 32,6 \\
& Jumlah & 43 & 100 \\
\hline
\end{tabular}

Tabel 2 menunjukkan bahwa sebanyak 29 sampel tahu positif formalin $(67,4 \%)$ dan $(32,6 \%)$ negatif formalin.
Adapun lokasi pedagang tahu yang mengandung formalin dapat dilihat pada tabel 2 .

\section{Tabel 3. Distribusi frekuensi kandungan formalin pedagang tahu berdasarkan lokasi di pasar tradisional Kota Serang}

\begin{tabular}{llccccc}
\hline \multirow{2}{*}{ No. } & & \multicolumn{4}{c}{ Pasar } & \multicolumn{3}{c}{ Total } & Tormalin \\
\cline { 3 - 6 } & & Positif & $(\%)$ & Negatif & $(\%)$ & \\
\hline 1. & Lama & 3 & 60 & 2 & 40 & 5 \\
2. & Taman sari & 6 & 75 & 2 & 25 & 8 \\
3. & Rau & 20 & 74,1 & 7 & 25,9 & 27 \\
4. & Kalodran & 0 & 0,0 & 3 & 100 & 3 \\
& $\quad$ Jumlah & 29 & 67,4 & 14 & 32,6 & 43 \\
\hline
\end{tabular}

Hasil analisis diketahui bahwa dari

43 sampel tahu di pasar tradisional Kota Serang, sebanyak 29 sampel tahu $(67,4 \%)$ positif mengandung formalin terdapat di Pasar lama sebanyak 3 sampel tahu (60\%), pasar taman sari sebanyak 6 sampel tahu (75\%), pasar rau sebanyak 20 sampel tahu
$(74,1 \%)$, dan pasar kalodran dari tiga sampel tahu seluruhnya negatif tidak mengandung formalin. 
Tabel 4. Distribusi frekuensi pengetahuan pedagang tahu di Pasar Tradisional Kota Serang

\begin{tabular}{cccc}
\hline No. & Pengetahuan & Frekuensi & $(\%)$ \\
\hline 1. & Tidak Baik & 25 & 58,1 \\
2. & Baik & 18 & 41,9 \\
& Jumlah & 43 & 100 \\
\hline
\end{tabular}

Hasil analisis diatas diketahui pedagang tahu $(58,1 \%)$ berpengetahuan bahwa dari 43 pedagang tahu pasar tidak baik dan 18 pedagang tahu $(41,9 \%)$ tradisional Kota Serang, sebanyak $25 \quad$ berpengetahuan baik.

Tabel 5. Distribusi frekuensi sikap pedagang tahu di Pasar Tradisonal Kota Serang

\begin{tabular}{cccc}
\hline No. & Sikap & Frekuensi & $(\%)$ \\
\hline 1. & Tidak Baik & 23 & 53,5 \\
2. & Baik & 20 & 46,5 \\
& Jumlah & 43 & 100 \\
\hline
\end{tabular}

Hasil analisis diketahui sebanyak

43 pedagang tahu pasar tradisional Kota Serang, sebanyak 23 pedagang tahu
$(53,5 \%)$ bersikap tidak baik dan 20 pedagang tahu $(46,5 \%)$ bersikap baik

Tabel 6. Distribusi frekuensi pengawasan pada pedagang tahu di pasar tradisonal Kota Serang

\begin{tabular}{cccc}
\hline No. & Pengawasan & Frekuensi & $(\%)$ \\
\hline 1. & Ada & 34 & 79,1 \\
2. & Tidak Ada & 9 & 20,9 \\
& Jumlah & 43 & 100 \\
\hline
\end{tabular}

Hasil analisis didapati dari 43 pedagang tahu di pasar tradisional Kota Serang, sebanyak 25 pedagang tahu
$(79,1 \%)$ menyatakan tidak mendapatkan pengawasan dan 9 pedagang tahu $(20,9 \%)$ menyatakan mendapat pengawasan 
Tabel 7. Hubungan antara pengetahuan dengan kandungan formalin pedagang tahu di pasar tradisional Kota Serang

\begin{tabular}{llcccccc}
\hline No. & Pengetahuan & \multicolumn{3}{c}{$\begin{array}{c}\text { Kandungan Formalin Pedagang } \\
\text { Tahu di Kota Serang }\end{array}$} & Total & p value \\
\cline { 3 - 6 } & & Positif & \multicolumn{3}{c}{ Negatif } & & \\
\cline { 3 - 6 } & & $\mathrm{N}$ & $\%$ & $\mathrm{~N}$ & $\%$ & & \\
\hline 1. & Tidak Baik & 21 & 84,0 & 4 & 16,0 & 25 & 0,016 \\
2. & Baik & 8 & 44,4 & 10 & 55,6 & 18 & \\
\hline
\end{tabular}

Analisis hubungan diperoleh nilai

$(P v=0,016)$ dengan nilai $(\mathrm{OR}=6,5)$.

Pengetahuan pedagang tahu yang tidak baik memiliki peluang risiko 6,5 kali tahu positif mengandung formalin dibandingkan pengetahuannya baik.

Tabel 8. Hubungan antara sikap dengan kandungan formalin pedagang tahu di pasar tradisional Kota Serang

\begin{tabular}{llcccccc}
\hline No. Sikap & \multicolumn{3}{c}{$\begin{array}{c}\text { Kandungan Formalin Pedagang } \\
\text { Tahu di Kota Serang }\end{array}$} & Total & p value \\
\cline { 3 - 6 } & & Positif & \multicolumn{3}{c}{ Negatif } & \\
\cline { 3 - 6 } & & $\mathrm{n}$ & $\%$ & $\mathrm{~N}$ & $\%$ & & \\
\hline 1. & Tidak Baik & 16 & 69,6 & 7 & 30,4 & 23 & 1,000 \\
2. & Baik & 13 & 65,0 & 7 & 35,0 & 20 & \\
\hline
\end{tabular}

Penelitian menunjukkan hasil tidak

terdapat hubungan signifikan antara sikap dengan kandungan formalin pada pedagang tahu. $(P v=1,000)$

Tabel 9. Hubungan antara pengawasan dengan kandungan formalin pedagang tahu di pasar tradisional Kota Serang

\begin{tabular}{llcccccc}
\hline No. & Pengawasan & \multicolumn{3}{c}{$\begin{array}{c}\text { Kandungan Formalin Pedagang } \\
\text { Tahu di Kota Serang }\end{array}$} & Total & p value \\
\cline { 3 - 6 } & & Positif & \multicolumn{3}{c}{ Negatif } & & \\
\cline { 3 - 6 } & & $\mathrm{n}$ & $\%$ & $\mathrm{~N}$ & $\%$ & & \\
\hline 1. & Tidak Ada & 27 & 79,4 & 7 & 20,6 & 34 & 0,004 \\
2. & Ada & 2 & 22,2 & 7 & 77,8 & 9 & \\
\hline
\end{tabular}

Penelitian menunjukkan hasil hubungan signifikan antara pengawasan dengan kandungan formalin pada pedagang tahu. $(P v=0,004)$. Pedagang tahu tidak mendapatkan pengawasan mempunyai peluang menjual tahu 
berformalin 13,5 kali dibandingkan yang mendapatkan pengawasan.

\section{PEMBAHASAN}

\section{Gambaran Kandungan Formalin Tahu}

Hasil analisis penelitian dari 43 sampel tahu sebanyak $29(67,4 \%)$ positif mengandung formalin diantaranya pasar lama sebanyak 3 sampel tahu $(60 \%)$, taman sari sebanyak 6 sampel tahu $(75 \%)$, rau sebanyak 20 sampel tahu (74,1\%), dan sampel kalodran seluruhnya negatif. Penelitian Lakuto dkk, (2017) menemukan kandungan formalin pada tahu sebesar (92,8\%). Syarfaini,Rusmin (2014), menemukan bahwa dari 15 sampel tahu di delapan pasar tradisonal Kota Makassar sebanyak 5 sampel tahu $(33,3 \%)$ positif mengandung formalin. Hasil observasi dilapangan terhadap karakteristik fisik tahu berformalin di pasar tradisional Kota Serang diantaranya tekstur kenyal, warna cerah tampak mengkilat, tekstur lebih banyak berongga dan jika dijatuhkan tahu akan memantul. Rekomendasi BPOM Republik Indonesia tahun 2018, menunjukkan bahwa ciri-ciri fisik tahu berformalin diantaranaya adalah tekstur kenyal, tidak mudah hancur, awet, dan berbau khas formalin, bukan bau khas tau.
(BPOM, 2018). Masih maraknya tahu berformalin. Diduga akibat biaya murah dan banyak dipasaran membuat produsen tahu masih memilih formalin. Peran perilaku manusia menjadi faktor utama penggunaan formalin pada produk tahu. Upaya untuk meningkatkan pengetahuan dan kesadaran pedagang tahu mengidentifikasi formalin, bahaya penggunaan dan pengolahan makanan dapat meningkatkan keamanan bahan pangan dan kesehatan masyarakat. (Wijaya dkk, 2012)

\section{HASIL}

\section{Pengetahuan}

Hasil penelitian menunjukkan bahwa dari 43 pedagang tahu di pasar tradisional Kota Serang, sebanyak 25 pedagang tahu $(58,1 \%)$ berpengetahuan tidak baik dan 18 pedagang tahu $(41,9 \%)$ berpengetahuan baik. Berdasarkan hasil pengamatan di lapangan menunjukkan bahwa pengetahuan tidak baik pada pedagang tahu di pasar tradisional Kota Serang diantaranya kurangnya pengetahuan (bentuk, sifat dan kemanfatannya termasuk bahan pengawet yang dizinkan). Penelitian terkait pengetahuan yang rendah menjadi faktor 
dominan dalam praktiknya. Salta dan

Citosan belum dimanfaatkan sebagai bahan pengawet. (Arumsari dkk, 2017). Faktor predisposisi seperti pendidikan formal diduga berpengaruh terhadap tingkat pengetahuan responden. Berdasarkan distribusi karakterisitk responden, tamatan SMP $(44,2 \%)$ dan SD $(30,2 \%)$. Pengetahuan berkorelasi dengan pendidikan, diharapkan semakin luas pengetahuannya. Terdapat signifikansi antara pengetahuan dengan tahu berformalin ( $\mathrm{p}$ value $=0,016<0,05$ ). Nilai $\mathrm{OR}=(6,563)$, Pengetahuannya tidak baik $(6,563)$ kali risiko lebih tinggi dengan tahu positif berformalin. Penelitian Arumsari dkk, (2017), menemukan bahwa faktor pengetahuan berpengaruh terhadap perilaku.

\section{Sikap}

Sikap merupakan faktor pendorong seseorang untuk berperilaku baik. Sikap tidak baik tidak sesuai dengan norma masyarakat. Hasil penelitian menemukan bahwa dari 43 pedagang tahu di pasar tradisional Kota Serang, sebanyak 23 pedagang tahu $(53,5 \%)$ bersikap tidak baik dan 20 pedagang tahu (46,5\%) bersikap baik. Berdasarkan hasil temuan dilapangan menunjukkan bahwa pedagang tahu pasar tradisional Kota Serang mengemukakan bahaya formalin bagi tubuh manusia, namun tidak mengganggu kesehatan dengan jumlah yang kecil. Responden mengatakan efektif sebagai pengawet. Terbentuk persepsi, tahu terasa enak, kenyal, tidak cepat rusak. Tidak terdapat hubungan sikap ( $\mathrm{p} v=1,000$; $>0,05)$. Sikap baik masih mengandung formalin (65\%). Safitri (2015) menemukan sikap negatif (35,3\%) terdapat formalin (+) sebesar 46,6\%. Sikap baik belum pasti menjadikan tindakan baik. Habibah (2013), menemukan sebaliknya sikap baik menjual tahu berformalin. Kesadaran masyarakat menjadi pertimbangan faktor sikap, menyebabkan keyakinan seseorang tidak baik. Pendidikan berkelanjutan memberikan perubahan persepsi negatif menjadi lebih baik.

\section{Pengawasan}

Penegakan hukum, pembinaan masyarakat mencegah penggunaan formalin. (Sutiari, Dwipayanti,2011) Hubungan signifikan pengawasan (p value $=0,004 ;<0,05)$. Nilai $(\mathrm{OR}=13,500)$, pengawasan $(13,5)$ kali risiko lebih tinggi 
dengan tahu berformalin. Pemeriksaan dan pembinaan berkelanjutan tidak dilakukan oleh Pemerintah Daerah Kota Serang, hanya rutin dilakukkan pada saat hari raya besar maupun menjelang bulan puasa saja. Lemahnya sanksi, berakibat pelaku berulang melakukan pelanggaran. Pencegahan melalui pendidikan jangka panjang, pengawasan penggunaan bahan berbahaya tambahan makanan oleh instansi yang berwenang setempat. (Hartati,2007)

\section{KESIMPULAN}

Kesimpulan dalam penelitian ini adalah dari 43 sampel tahu di pasar tradisional Kota Serang, sebanyak 29 sampel tahu $(67,4 \%)$ positif berformalin. Faktor penyebab dari hal tersebut adalah pengetahuan pedagang tahu merupakan faktor risiko 6,5 kali tahu yang dijual mengandung formalin dan pengawasan memiliki risiko 13,5 kali tahu yang dijual mengandung formalin. Sanksi tegas bagi pelaku yang melanggar. Pembinaan persuasif dilakukan pada pedagang tahu pasar Kota Serang.

\section{UCAPAN TERIMAKASIH}

Ucapan terimakasih kepada pihakpihak terkait terutama pada Dinas Kesehatan Kota Serang, seluruh pasar tradisional di Kota Serang dan Universitas Faletehan.

\section{DAFTAR PUSTAKA}

Arumsari, G.P., Krianto, T., \& Wispriyono, B. (2017). Perilaku Penggunaan Formalin Pada Pedagang Dan Produsen Mie Basah Dan Tahu Di Provinsi DKI Jakarta. Jurnal Kesehatan Masyarakat Andalas. Vol. 11, No. 1, Hal. 39-48.

Arikunto, S. (2010). Manajemen Penelitian. Jakarta: Rineka Cipta.

BPOM, RI. (2019). Laporan Tahunan Kegiatan Tahun 2018. Jakarta: Direktorat Pemberdayaan Masyarakat Dan Pelaku Usaha Deputi Bidang Pengawasan Pangan Olahan Badan POM.

Dinas Kesehatan Kota Serang. (2018). Laporan Tahunan Bidang Farmasi dan Alat Kesehatan Kota 
Serang 2017. Serang: Dinas

Kesehatan Kota Serang.

Desrosier, Norman,W. (2008). Teknologi Pengawetan Pangan. Jakarta: UIPress.

Habibah, T. (2013). Identifikasi Penggunaan Formalin Pada Ikan Asin dan Faktor Perilaku Penjual di Pasar Tradisional Kota Semarang. Jurnal: Unnes Journal of Public Health. 2 (3) (2013).

Hartati, H. (2007). Analisis Manajemen Pengawasan dan Pengendalian Penyalahgunaan Formalin di Dinas Kesehatan Kabupaten Tangerang. KESMAS, Jurnal Kesehatan Masyarakat Nasional. Vol. 2, No. 2, Oktober 2007.

Lakuto, R.S., Akili, R.H., \& Joseph, W.B.S. (2017). Analisis Kandungan Formalin Pada Tahu Puth Di Pasar Bersehati Kota Manado Tahun 2017. KESMAS. Jurnal Kesehatan Masyarakat Universitas Sam Ratulangi. Volume 6, Nomor 3, Mei 2017.
Saparinto, C., Hidayati, D. (2006). Bahan Tambahan Pangan. Yogyakarta: Kanisus.

Syarfaini, Rusmin, M. (2014). Analisis Kandungan Formalin Pada Tahu di Pasar Tradisional Kota Makassar Tahun 2014. Al-Sihah: Public Health Science Journal. Volume VI,No.2, Juli-Desember 2014.

Sutiari, N.K., Dwipayanti, U. (2011). Pembinaan Pedagang Tahu Di Pasar Badung Mengenai Bahaya Penyalahgunaan Formalin. Udayana Mengabdi Volume 10 Nomor 1 Tahun 2011.

Safitri, A.R. (2015). Gambaran Pengetahuan, Sikap, Dan Perilaku Penjual Tahu Mengenai Tahu Berformalin Di Pasar Daerah Semanan Jakarta Barat Tahun 2015. Skripsi: Universitas Islam Negeri Syarif Hidayatullah Jakarta. 
Wijaya,C.H., Mulyono, N., \& Afandi, F.A. (2012). Bahan Tambahan Pengawet. Bogor: IPB Press. 